\title{
Judíos y redes personales en Tierra de Campos durante la segunda mitad del siglo XV: un Cuaderno de Minutas de Avecindamientos de Villalón
}

\author{
Javier Castaño, ILC - CSIC \\ Susana del Rey Granell*
}

\begin{abstract}
En las décadas centrales del siglo xv algunos judíos fueron inscritos por las autoridades concejiles como vecinos en distintas localidades castellanas. Tradicionalmente, la vecindad se había caracterizado como una categoría de pertenencia a una comunidad política local, cuya participación estaría vetada a los judíos al considerarlos como una casta religiosa. Partiendo del estudio de documentación inédita relativa a la localidad castellana de Villalón -en un momento de auge de sus ferias impulsadas por el IV conde de Benavente- en Tierra de Campos, durante los años de desorden político general del reino, se propone una interpretación del avecindamiento de judíos que privilegia las relaciones de subordinación de la aljama respecto del concejo. Con ayuda de otras fuentes documentales, se ofrece un esbozo de las redes personales de judíos, subrayando el protagonismo de los médicos.
\end{abstract}

PALABRAS ClavE: Historia de los judíos; Castilla; prosopografía; vecindad; cultura manuscrita hebrea; médicos judíos.

Jews and Personal Networks in Tierra de Campos during the Second Half of the Fifteenth Century: A Notebook of the Memoranda of Citizenship of Villalón.- In the middle decades of the fifteenth century Jews were registered as local citizens in the municipal council records of individual Castilian towns. Traditionally, a citizen was recorded as belonging to a parish or parochial neighborhood within the local political community; this would exclude Jews by definition as they were designated separately as a religious caste. The study of unpublished documents related to the Castilian locale of Villalón -characterized by the economic importance of its fairs promoted by the $4^{\text {th }}$ count of Benavente- in the region of Tierra de Campos during a period of general political disorder, records that the municipal council assigned citizenship to Jews in relation to their community (aljama) through which specific aspects of their lives were regulated, and by which the local council rather than other political instances assumed control of that community. With the help of other primary sources, these documents reveal the suggestion of personal networks in which Jewish physicians play a key role.

KeYwords: History of the Jews; Castile; Prosopography; Citizenship (in Local Communities); Hebrew Manuscript Culture; Jewish Physicians.

\footnotetext{
*javier.castano@cchs.csic.es; sdr1.granell@gmail.com
} 
El 12 de septiembre de 1471 rabý Abrahán Alhanate recibía la vecindad por diez años en Villalón, localidad de Tierra de Campos. Aquella estaba vinculada al desempeño del oficio médico al servicio del concejo. En el acto de avecindamiento celebrado ante el corregidor y regidores, su tío rabý Mosé Alhanate salía como fiador. La relación que se establecía entre el judío y este concejo de señorío era a la vez de naturaleza cívica (la vecindad era una categoría que implicaba pertenencia a una comunidad) y laboral, y no es casual la coincidencia de ambas facetas: en su intento por asegurar la atención sanitaria para potenciar el atractivo ofrecido por la villa, el concejo incorporaba a un individuo cualificado. El hecho no es excepcional, porque el fenómeno del avecindamiento temporal de judíos se testimonia, al menos, a lo largo de las décadas centrales del siglo XV en otras localidades de la Corona de Castilla. En cuanto a la relación laboral, su contrato ejemplifica la presencia activa de judíos en una cada vez más tupida red de asistencia médica que se va tejiendo por toda la geografía castellana, y que es posible estudiar con algún detalle durante estas mismas décadas: al igual que don Yuçá, un «físico» asalariado del concejo de Palencia, admitido en 1458 como vecino por diez años en esa ciudad ${ }^{1}$, rabý Abrahán Alhanate recibía una serie de franquicias fiscales «mientra él aquý vevyere e usare del ofiçio de físico».

El avecindamiento de rabý Abrahán Alhanate tampoco es inusual en su marco local: sólo durante el quinquenio 1471-1475, en pleno «deshorden del tienpo» ${ }^{2}$ que caracteriza la etapa final del reinado de Enrique IV, 22 judíos recibían la vecindad en Villalón, lo que representa un tercio del total de nuevos vecinos computados. En buena medida -así ocurre con 12 de ellos-, estos judíos mantenían estrechos lazos de parentesco con otros vecinos que garantizan el cumplimiento de las obligaciones contraídas: el mismo rabý Abrahán Alhanate actúa como fiador de su madre doña Vellida de Cuenca (de Campos), mujer del «físico» rabý Salamón de Cuenca (de Campos), la cual tomaba vecindad el 5 de noviembre de 1472 ante el corregidor, alcaldes y regidores por diez años. Para ello, aportaba un año después una carta del conde de Benavente, señor jurisdiccional de la villa. Y algo más tarde, el 7 de julio de 1474, rabý Abrahán actúa de fiador de su hermano, también «físico», rabý Sentó Alhanate, que recibe vecindad por diez años.

Precisamente, una de las cuestiones sometidas a debate entre historiadores de los judíos se refiere a su acceso a la vecindad en villas y ciudades bajo-

\footnotetext{
${ }^{1}$ Pilar León Tello, Judios de Palencia (Palencia 1967), doc. 143; María Jesús Fuente Pérez, Palencia. Cien años de vida y gobierno de la ciudad (1421-1521) a través de las actas municipales (Palencia 1987), págs. 28-33 y 92; única mención conocida al avecindamiento en Palencia de un judío.

${ }^{2}$ Según rotulan las Cortes de 1473 (pet. 16); para esta y las siguientes menciones remitimos a la edición de Cortes de los Antiguos Reinos de León y de Castilla (Madrid 1866), tomo III.
} 
medievales ${ }^{3}$. Partiendo de la descripción y análisis del ejemplo de Villalón, intentaremos iniciar la discusión acerca de algunos significados posibles del avecindamiento de judíos en el contexto de la Castilla urbana del siglo XV. De entrada, la vecindad, que estaba vinculada a la construcción del cuerpo cívico local, parecía excluir la participación de los judíos, que por motivos religiosos habían sido tradicionalmente caracterizados como una casta. Sin embargo, el estudio del vínculo cívico horizontal que mantienen los judíos, en tanto que individuos, con el resto de habitantes de las ciudades y villas donde viven, ha venido siendo preterido en favor de otros vínculos de dependencia política verticales mejor conocidos. No es necesario recordar que, pese a su reconocimiento como corporación, la aljama carecía de una genuina autonomía políti$\mathrm{ca}^{4}$, aunque falta por determinar el alcance de las intromisiones externas de la alta nobleza y las interferencias de los concejos, que incluyen desde exacciones fiscales indebidas - repetidamente desautorizadas por la Corona ${ }^{5}$ - hasta intentos de regulación demográfica.

El crecimiento de la población judía en localidades de señorío a lo largo del siglo XV es un fenómeno conocido, ya advertido por los coetáneos, que está estrechamente relacionado con el desarrollo de los estados señoriales. A fines de la década de 1420, un analista vinculado a la Hacienda real denunciaba en un lúcido memorial dirigido al monarca la aparente contradicción en la que incurrían aquellos señores que, tras lograr la promulgación de ordenanzas restrictivas, habían acogido en sus estados a judíos a los que previamente empujaron a abandonar las ciudades de realengo ${ }^{6}$.

${ }^{3}$ Como apunta Ariel ToAfF, «Judei cives ? Gli ebrei nei catasti di Perugia del Trecento», Zakhor 4 (2000), págs. 11-36. Reflexiones generales adaptadas a otro marco regional, en Alfred HAVerKAMP, «'Concivilitas' von Christen und Juden in Aschkenas im Mittelalter», en Jüdische Gemeinden und Organisationsformen von der Antike bis zur Gegenwart, Hg. Robert JütTE, Abraham P. Kustermann (Wien 1996), págs. 103-136.

${ }^{4}$ Maurice Kriegel, Les juifs à la fin du Moyen Âge dans l'Europe méditerranéenne (Paris 1979), págs. 113-115.

${ }^{5}$ Según se ordena desde 1437 , alegando que los judíos ya pagaban pechos apartadamente y no estaban obligados a las derramas indebidas distribuídas por los concejos. Entre estas se mencionan en 1447: «pechos e tributos, martiniegas, foreros e enprestidos e derramas e pedidos e otros pechos e derechos e salarios»; y en 1453: «enprestidos e derramas e lievas de pan e de otras cosas nin vallesteros nin lançeros nin omes de armas e peones e tributos e ayudas e salarios e pechos foreros e otras fasenderas [...], salvo en puente e en fuente e çerca e termino si e segund que lo han acostumbrado» [la cursiva es nuestra], en Luis SuÁREZ FERnÁndEZ, Documentos acerca de la expulsión de los judíos (Valladolid 1964), doc. 23.

${ }^{6}$ Miguel Ángel Ladero Quesada, La Hacienda real de Castilla en el siglo XV (La Laguna 1973), pág. 337. 
Si nos centramos en un ámbito regional específico, el de Tierra de Campos, se puede observar que, tras un periodo inicial, a comienzos del siglo XV, de violencias derivadas en conversiones y abandono de sinagogas -como sucedió, al menos, en Benavente, Cisneros, Mayorga, Palencia, Paredes, Toro y Valencia de Don Juan-, el proceso de señorialización puesto en marcha y estabilizado a partir de la década de 1430, garantizaba a los judíos, como al resto de la sociedad, cierto orden gracias a la cercanía de una instancia efectiva de poder. Tomando como referencia el repartimiento del «servicio y medio servicio» de 1464, es manifiesta la importancia ascendente de los judíos de Tierra de Campos, en especial en Villalón, la contribución fiscal de cuya aljama dentro del obispado de Palencia sólo aparece superada por la conjunta de las de Aguilar de Campos y Medina de Rioseco ${ }^{7}$.

\section{Los Pimentel en Villalón}

Villalón de Campos, al noroeste de Valladolid, se integra en el estado señorial del II conde de Benavente a partir de 1434. La villa no era para sus señores «un punto más de su señorío, sino uno de sus centros principales de poder» ${ }^{8}$, gracias a la prosperidad económica alcanzada a lo largo de la segunda mitad del siglo XV y comienzos del XVI, con el desarrollo de su feria de Cuaresma que la singulariza del resto de villas agrarias vecinas (a excepción, claro está, de Medina de Rioseco). El declive económico posterior, que acaba desdibujando parte de su fisonomía original de la que aún quedan huellas, hizo diluir una realidad caracterizada por la vitalidad mercantil, demográfica y económica que experimenta a lo largo de la segunda mitad del Cuatrocientos. De forma paralela es difícil reconstruir una presencia judía desvanecida, de la que ignoramos casi todo, no sólo respecto a Villalón, sino al resto de la comarca, debido a la escasez de investigaciones ${ }^{9}$.

${ }^{7}$ Miguel Ángel Ladero QuesadA, «Las juderías de Castilla según algunos “servicios” fiscales del siglo XV», Sef 31 (1971), págs. 249-264: 257.

${ }^{8}$ Isabel Beceiro Pita, El condado de Benavente en el siglo XV (Salamanca 1998), pág. 65.

${ }^{9}$ La colección documental de León Tello citada anteriormente contiene menciones a judíos asentados en núcleos del sector oriental de Tierra de Campos, especialmente Paredes de Nava. Además, véase Francisco CANTERA Burgos, «La administración judía del duque de Nájera en la aljama palentina de Amusco», en Hommage à Georges Vajda. Études d'histoire et de pensée juives, ed. Gérard NAHON et Charles Touati (Louvain 1980), págs. 309-321. Acerca de los judíos del sector leonés, ID., «Juderías medievales de la provincia de León», Archivos Leoneses 55-56 (1974), págs. 85-155. Algunos estudios de factura local ofrecen datos que necesitan ser verificados, véase Carlos Duque Herrero, «Mudéjares y judíos en Villalón en el siglo XV», El Trijón 23 (1998), págs. 36-40, ampliado en ID., Villalón de Campos. Historia y patrimonio artístico (del 
Al referirse al señorío de los Pimentel, Isabel Beceiro señalaba que «en líneas generales, se puede afirmar que los asuntos de carácter local fueron dejados al arbitrio de los municipios» ${ }^{10}$, por lo que para entender la creciente presencia de judíos en Villalón a lo largo de la segunda mitad del siglo XV hay que tener en cuenta las necesidades no sólo económicas sino también de asistencia sanitaria de una villa que experimenta un crecimiento continuo a causa de la feria.

Carecemos de información documental acerca del asentamiento judío en Villalón previo al siglo XV. No obstante, en febrero de 1412, al poco de producirse el primer apartamiento, el concejo de Paredes enviaba un delegado a la villa «a saber cómmo auían fecho de los judíos»" ", por lo que a juzgar por el funesto desenlace de acontecimientos en Paredes donde desaparece la aljama, se puede deducir que la situación en Villalón no sería mucho mejor.

Los comienzos del señorío de los Pimentel sobre Villalón coinciden con el contrato asalariado en 1437 por seis años del «físico» don David Çamanón, recibido como médico del concejo. No se le llega a conceder formalmente la vecindad, a diferencia de lo que ocurre tres décadas más tarde con rabý Abrahán Alhanate $^{12}$. Eso no obsta para que el mismo día en que se documenta su contrato el concejo acepta el avecindamiento de Yudá de Aguilar por diez años, el cual presentaba a un cristiano como fiador ${ }^{13}$.

Coetáneo de ambos es otro judío, Abraán Comineto de Villalón, que en 1446 toma vecindad en Orense por cinco años, permitiéndole gozar de todos los privilegios de los vecinos de la ciudad, y la exención de derramas («maravedíes e pedidos et moedas e tallas conçellaudas que se deytaren et derramaren enna dita çibdade»), a cambio del pago de una cantidad anual ${ }^{14}$. Se puede sugerir la

siglo XIV al XVI) (Palencia 2006), págs. 50-53 y 114-117; Inocencio CADIÑANOS BARDECí, «Nuevas noticias de la judería de Villalpando: sus actividades prestamistas, el barrio y la sinagoga», $E l$ Olivo año XXVII, n. ${ }^{\circ} 58$ (2003), págs. 15-28.

${ }^{10}$ Beceiro Pita, El Condado de Benavente, págs. 271-272.

${ }^{11}$ Juan Carlos Martín CeA, «Los judíos de Paredes de Nava: la desaparición de una aljama palentina en 1412», en Actas del I Congreso de Historia de Palencia (Palencia 1987), págs. 539552: 546.

${ }^{12}$ Archivo Municipal de Villalón (en adelante, AMVillalón), caja 1, carp. 2, Actas del Concejo 1436-1487, f. ${ }^{\circ} 19 \mathrm{v}$.

${ }^{13}$ Con motivo del segundo apartamiento de judíos (1482) se menciona la «casa de la de Yudá de Aguilar», Archivo de la Real Chancillería, Valladolid (en adelante, ARCh), Protocolos y Padrones, caja 165, n. ${ }^{\circ}$ 6, Actas del Concejo de Villalón 1482, f. ${ }^{\circ} 15$ r.

${ }^{14}$ Véase Ma Gloria de Antonio Rubio, Los judíos en Galicia (1044-1492) (A Coruña 2006), págs. 38-40 («Los judíos documentados en las "avinzas" del concejo»); y doc. 188 (acta de avecindamiento de Abraán Cominero [léase, Comineto], 9-XII-1446), págs. 492-493. 
identificación de este Abraán con su homónimo mencionado en 1434 como recaudador en Benavente, hermano de Yudá Comineto, un destacado judío en la privanza del conde de Benavente, en cuyo nombre actúa recibiendo en vecindad a una cristiana, lo que resulta, cuando menos, inusual en un judío ${ }^{15}$.

El periodo que nos incumbe ahora es el del IV conde, Rodrigo Alfonso Pimentel (1461-1499), durante el cual se termina de configurar un señorío encabezado por Benavente, Villalón y Mayorga. Yerno del marqués de Villena, Pimentel se alinea desde 1468 junto a Enrique IV, lo que le permite beneficiarse de importantes dádivas como la tenencia y gobernación compartida de Valladolid, donde en 1470 se impone sobre el bando de Juan de Vivero ${ }^{16}$.

No por interesada es menos determinante la onerosa protección que el conde extiende sobre Villalón -concretada en diversos planos ${ }^{17}-$, y más en concreto sobre su feria, cuya existencia defiende ante sucesivos monarcas por los intentos de reducción generalizada de franquicias: así, cuando en 1473 las Cortes pretenden limitar la actividad ferial más importante del reino a varias ciudades de realengo ${ }^{18}$. La tentativa no era novedosa, pues se suceden precedentes en 1430 y en 1462, cuando los procuradores de las ciudades habían pedido poner coto a la proliferación de ferias francas en lugares de señorío que intentaban reproducir la fortuna del modelo de Medina del Campo ${ }^{19}$.

La proximidad a Valladolid y a las dos Medinas había favorecido el desarrollo de la feria de Cuaresma de Villalón (franca de alcabalas y de duración mínima de 30 días) ${ }^{20}$, iniciada tras una primera sanción regia durante la década de $1430^{21}$. El interés señorial por las ferias se justifica por lo que suponían de incremento de riqueza y población de la villa, que se intenta potenciar mediante la afluencia de mercaderes. El beneficio directo del conde radicaba en la fiscalización de mercancías (portazgo y diezmo al introducir los artículos, aunque los vecinos y moradores de Villalón estaban exentos de pagar el primero; y sisa, que se pagaba

\footnotetext{
${ }^{15}$ Acerca de ambos, véase Severiano Hernández Vicente, El concejo de Benavente en el siglo XV (Zamora 1986), págs. 135, 139 y 243.

${ }^{16}$ Beceiro Pita, El condado de Benavente, pág. 200.

${ }^{17}$ Por ejemplo, en la fundación en 1469-70 del convento franciscano observante de Santa María de Jesús, en Carlos DuQue Herrero, «Intervenciones artísticas de los condes de Benavente en Villalón (1434-1586)», Brigecio 12 (2002), págs. 15-42: 41.

${ }^{18}$ Cortes de 1473, pet. 19.

${ }^{19}$ Cortes de 1430 , pet. 25 ; y Cortes de 1462, pet. 5 .

${ }^{20}$ Beceiro Pita, El condado de Benavente, pág. 274 (privilegio real de 2-IV-1474).

${ }^{21}$ Una descripción somera de su desarrollo inicial en Miguel Ángel Ladero Quesada, Las ferias de Castilla. Siglos XII a XV (Madrid 1994), págs. 93-100 y 130-133.
} 
con la alcabala) y en una serie de derechos (suelos de la feria, aposentamiento, exhibición de productos en los bancos situados delante de las casas, retribuciones a alguaciles y alquileres de casas propiedad del noble). A ello había que añadir la venta de productos locales ajenos a la feria (sometidos al pago de alcabala), y el incremento del comercio habitual ${ }^{22}$. Razones de peso para proteger estas ferias, por lo que en años de atonía ferial se agregaban franquicias a fin de atraer mercaderes ${ }^{23}$, intentando paliar la competencia de otras nuevas en señoríos próximos, delimitando con sus titulares la duración y periodo de celebración, como ocurre con las de Cuenca de Campos, del conde de Haro.

Las ferias de Cuaresma reunían centenares de mercaderes, y las actas concejiles de 1482 registran la participación de especieros toledanos, valencianos, y moros de Arévalo y Ávila (todos ellos aposentados en la Costanilla): joyeros; espaderos, lanceros y caldereros; además de mercaderes pañeros, algunos portugueses, y mercaderes burgaleses de lana, tratantes de ganado y vendedores de pescado del Cantábrico $^{24}$, entre otros. A estas ferias asistían otros mercaderes portugueses a negociar la adquisición de cereal y un número significativo de sastres, también portugueses, en búsqueda de tejidos ${ }^{25}$. Progresivamente la feria va asumiendo funciones de feria de pagos, a semejanza de las de Medina del Campo y la de Medina de Rioseco. No obstante, no hemos encontrado aún referencias explícitas a la actividad directa de judíos, ni foráneos ni locales, en las ferias de Villalón, excepción hecha de alguna noticia aislada relativa al crédito comercial ${ }^{26}$, y el incremento sustancial de vecinos judíos en la villa a comienzos de la década de 1470.

Un repaso a las rentas condales de la villa testimonia su progresivo desarrollo mercantil ${ }^{27}$, para escándalo de coetáneos que, durante los años finales del reinado de Enrique IV, percibían con recelo el avance de algunos señoríos frente al realengo ${ }^{28}$.

${ }^{22}$ Una evaluación del valor económico de la feria a comienzos del siglo XvI, en su momento álgido, en Luis Fernández Martín, S. J., «La feria de Villalón durante la guerra de las Comunidades», Cuadernos de Investigación Histórica 2 (1978), págs. 215-236.

${ }^{23}$ Beceiro Pita, El Condado de Benavente, pág. 275.

${ }^{24}$ ARCh, Actas del Concejo de Villalón 1482, passim.

${ }^{25}$ Isabel VAZ DE Freitas, Mercadores entre Portugal e Castela na Idade Média (Gijón 2006), pág. 55.

${ }^{26}$ Es el caso del crédito concedido por rabí Santó, vecino de Villalón, a dos tratantes de San Vicente de la Barquera para pago de «los alquileres de cierta sardina que tenían en la villa», en ARCh, Ejecutorias, caja 21, n. ${ }^{\circ} 14$ (IV-1489), cit. M. ${ }^{a}$ Antonia VARONA GARCía, Cartas ejecutorias del Archivo de la Real Chancillería de Valladolid (1395-1490) (Valladolid 2001), § 970.

${ }^{27}$ Beceiro Pita, El Condado de Benavente, págs. 156-157 y 172.

${ }^{28}$ Como denuncian las Cortes de 1473, pet. 27. 


\section{Un CUADERNO DE MINUTAS DE AVECINDAMIENTOS}

Entre la documentación depositada en el Archivo Municipal de Villalón se custodia un fragmento de un cuaderno de avecindamientos que contiene las minutas del reconocimiento de vecindad otorgada a 118 individuos establecidos en esta villa entre 1471 y 1487 , de los que una cuarta parte, es decir, 30, eran judíos.

De este cuaderno se conservan diez folios cosidos -faltan los iniciales y los finales-, escritos cuidadosamente por ambas caras, con un orificio para permitir su ligadura ${ }^{29}$. La primera minuta registrada está fechada el 8 de febrero de 1471, y la última el 2 de enero de 1487, y su estudio permite determinar que estos avecindamientos son todos los que hubo. Para 1478 no hay datos porque en ese año «non se falló veçinos nuevos». Con distinta intensidad de tinta y trazo se realizan en el margen izquierdo anotaciones posteriores, ya entrada la década de 1480. Estas notas marginales especifican el nombre del individuo avecindado y el de su fiador, actualizando la información acerca de aquel: si aún permanece en la villa, si ha fallecido o si se ha mudado a otro lugar.

Las minutas registran el acto de avecindamiento y aparecen redactadas -a excepción, quizás, de las de 1485-87-, al igual que las anotaciones al margen, por una misma mano. Esa regularidad caligráfica podría hacer pensar que se trata de la copia de una minuta original. La relevancia del cuaderno en cuestión viene dada no tanto por la singularidad de su tipología documental dentro de la diplomática bajomedieval castellana ${ }^{30}$, como por dar noticia del avecindamiento de una treintena de judíos.

A través del análisis de las minutas de Villalón pretendemos dar alguna respuesta a interrogantes demográficos (vínculos familiares entre los nuevos vecinos y sus fiadores; matrimonio como motivo de avecindamiento; lugares de proveniencia, si procede) y sociales (oficios de los nuevos vecinos; caracterización de los fiadores); sin dejar de plantear los distintos significados y motivos del avecindamiento en el marco de las relaciones entre judíos y concejos.

Es revelador que la mayor parte de los avecindamientos se produzcan durante el quinquenio 1471-1475, en el que se registra la inclusión en los padrones de

\footnotetext{
${ }^{29}$ AMVillalón, caja 652, Cuaderno de Minutas de Avecindamientos.

${ }^{30}$ Fernando Pino Rebolledo, Tipología de los documentos municipales (siglos XII-XVII) (Valladolid 1991), págs. 143-151: 143. Una visión introductoria general con reflexiones interesantes en Susana ROYER DE CARDINAL, «Algunos aspectos de las migraciones en la Castilla del siglo XV», Fundación 1 (1997-1998), págs. 101-189: 127-132.
} 
22 judíos, que suponen un tercio de los 63 nuevos vecinos. La oscilación anual de los avecindamientos es bastante irregular: a partir de 1476 se reduce drásticamente el número de vecindades, anotándose sólo cinco entre 1477 y 1481, que se reducen a tres entre 1482 y 1485 . Mientras que en 1474 y 1475 se avecindan cada año seis judíos (de un total de 13 y 19 nuevos vecinos respectivamente); en 1472 son cuatro judíos (de nueve avecindados); en 1471, 1473 y 1481, tres (de 11,11 y 9 , respectivamente), mientras que en 1476, 1478, 1480, 1483, 1486 y 1487 no se avecinda ninguno.

La nómina nos brinda cincuenta y dos nombres de judíos, así como detalles de sus identidades. De ellos, treinta son nuevos vecinos y veintidos los fiadores, todos varones que tomaban vecindad como cabeza de familia, a excepción de una mujer (¿viuda?), doña Vellida de Cuenca (de Campos).

Los avecindamientos se conceden a lo largo del año, si bien la mitad de ellos lo fueron entre enero y marzo, inclusive, y no parece casual la coincidencia con la celebración de la feria de Cuaresma. El parentesco es clave para alcanzar la vecindad en, al menos, casi la mitad de los nuevos vecinos (14), y ello determina la identidad del fiador. En determinadas circunstancias, el motivo del avecindamiento es la emancipación del hogar familiar por parte de hijos (2) o de hermanos (2).

Dos individuos toman a sus tíos como garantes, a falta de un progenitor en la villa que lo hiciera. Se eleva a cinco el número de suegros que aparecen como garantes de sus yernos, al ser el matrimonio una de las vías de acceso a la vecindad. Encontramos también a un hijo que hace de fiador de su madre, además de dos judíos emparentados en grado indeterminado con el fiador. Las anotaciones marginales revelan que tres de los nuevos vecinos fallecen durante la década de 1480: rabý Abrahán Bellamýn, Mosé Cabeça y Mosé Viejo.

La procedencia de los avecindados forasteros se señala sólo en seis casos, y salvo Cáceres, el resto de los lugares se sitúa dentro de un radio de $45 \mathrm{~km}$ alrededor de Villalón: Carrión (45 km); Cea (40 km); Medina de Rioseco, y Grajal, junto a Sahagún $(24 \mathrm{~km})$; y Cuenca de Campos (5 km). Para alguno, Villalón no es un destino definitivo, como le ocurre a rabý Abrahán Bellamýn, que abandona la villa para instalarse en Castroponce (a $13 \mathrm{~km}$ ), donde fallece. Como además alguno de los apellidos de los nuevos vecinos se repite en localidades cercanas, como Villalpando (Cabeça, Bellamín, Villalobos) o Sahagún (Obadiá, Abén Pex), podemos suponer que Villalón actúa, durante las décadas anteriores a 1480, como polo de atracción para judíos de su comarca más inmediata. 


\subsection{Perfiles individuales}

El avecindamiento es un acto jurídico que suponía ventajas para el individuo, al pasar a gozar de los privilegios comunes al resto de vecinos de la localidad. Su concesión era potestad del concejo y no implicaba necesariamente un cambio de residencia, porque era habitual que el individuo ya estuviera asentado en la localidad. Para conceder la vecindad, lo que se hacía por un periodo limitado de años, se requería la presentación de un fiador que diera garantías.

Constituye un lugar común la mención de tres requisitos exigidos para la adquisición de vecindad: propiedad de bienes raíces, residencia y permanencia en la localidad, y pecha, aunque no siempre era así, produciéndose diferencias sustanciales según las circunstancias ${ }^{31}$. Una vez avecindado, el individuo comenzaría a gozar de alguna de las franquicias de las que disponían los otros vecinos de la localidad, pero a veces debía pasar un plazo para disfrutar de vecindad plena.

Aunque contamos con investigaciones demográficas de libros de avecindamientos relativas a otros ámbitos geográficos ${ }^{32}$, salvo alguna importante excepción puntual carecemos de estudios que se refieran a localidades castellanas ${ }^{33}$, lo que no siempre se justifica por una pretendida carencia de fuentes documentales $^{34}$.

${ }^{31}$ M. a del Carmen CARLÉ, Del concejo medieval castellano-leonés (Buenos Aires 1968), págs. 83-90; una rigurosa exposición teórica en Juan I. RuIz DE LA PEÑA, «Las solidaridades vecinales en la Corona de Castilla (Siglos XII-XV)», en Cofradías, gremios, solidaridades en la Europa Medieval (Pamplona 1993), págs. 51-73: 64-69

${ }^{32}$ Partiendo de los «Llibres de avehinament», Piles distinguía entre avecindamiento y simple concesión de franquicias, y anota ocho casos de judíos avecindados en Valencia entre 1368-1384, véase Leopoldo Piles Ros, La judería de Valencia (estudio histórico). Edición, revisión y notas por José R. Magdalena Nom de Déu (Barcelona 1991), págs. 58-62; y M. a de los Desamparados Cabanes Pecourt, «Avehinaments»(Valencia, s. XIV) (Valencia 2000), que permite elevar a 18 el número total de judíos avecindados durante ese periodo, cifra que resulta modesta en relación al total de nuevos vecinos.

${ }^{33}$ Excepcional es el caso de la «cuadrilla» de Castejón en Huete (1415-1435) para el que contamos con el estudio de Luisa NAVARRo DE LA TORRE, «Avecindamientos en Huete al comenzar el siglo XV», en 1490. En el umbral de la modernidad. El Mediterráneo europeo y las ciudades en el tránsito de los siglos XV-XVI, ed. José Hinojosa Montalvo, Jesús PRAdells Nadal (Valencia 1994), vol. II, págs. 693-711: 695. Al tratarse del registro de un barrio alejado de la judería no sorprende la ausencia de judíos entre los 136 avecindados.

${ }^{34}$ Como muestra un repaso a la amplia actualización bibliográfica recogida en Germán NAVARRo EsPINACH, «Política municipal y avecindamientos. Análisis de la emigración aragonesa a Valencia (1308-1526)», en Demografía y sociedad en la España bajomedieval. Sesiones de trabajo. Seminario de historia medieval (Zaragoza 2002), págs. 97-128: 99-106. 
Dada su exclusión religiosa y social de la sociedad corporativa cristiana, resulta una obviedad señalar que el avecindamiento de judíos no los sitúa automáticamente al nivel cívico y social de sus conciudadanos cristianos, ya que era difícil que participaran de algunos de los derechos inherentes a la vecindad (como, por ejemplo, el disfrute de los bienes de propios o la intervención en la gestión del concejo).

Echemos una ojeada a los perfiles de alguno de los judíos avecindados. De dos de ellos, Abrahán Querido y Simuel Navarro, obtenemos detalles a través de la escueta información que nos facilitan las minutas, pero también de la más extensa suministrada por las actas concejiles.

Aunque carecemos de detalles de su biografía, sabemos que Abrahán Querido procede de Grajal, junto a Sahagún. El desconocimiento de la composición demográfica de las juderías de la comarca nos impide averiguar si su familia estaba arraigada en Tierra de Campos. La ausencia de huellas de su apellido en Castilla, que no en Portugal ${ }^{35}$, nos conduce a un problema más amplio que reclama un estudio detallado: el de la movilidad de judíos de un lado al otro de la Raya, estimulada por la continuidad geográfica, y por circunstancias políticas coyunturales.

Abrahán Querido toma «de su voluntad propia» vecindad en enero de 1481 ante el corregidor Alonso Ternero. El recurso a dos relevantes fiadores permite conjeturar vínculos previos a su establecimiento en Villalón: Abrahán Tamar, al que vemos como arrendador de la «sisa de la carne y vino judiegos», y Simuel, platero. Recibe vecindad por diez años con «todas las franquesas e libertades que dauan a otros vesinos nueuos», además de una exención de «huéspedes». Es infrecuente la elevada penalización fijada, 100.000 mrs., en caso de incumplimiento de la obligación de vivir en la villa durante ese periodo, que hay que sumar a la cuantía ocasionada por daños. Por ese motivo, se añade una cláusula con la que el nuevo vecino guarda a sus fiadores de cualquier menoscabo. Su acto de avecindamiento incluye además la pretensión de «ser vasallo del conde», en otras palabras, una relación de dependencia personal. Si la cuantía de la penalización refleja una alta capacidad económica, queda de manifiesto el interés por establecerlo en el señorío.

Distinto es el avecindamiento de Simuel Navarro por diez años, que tiene lugar el 3 de mayo de 1482, días después de que el concejo decretara el apartamiento de los judíos que se lleva a cabo entre el 7 y 21 de mayo. En su caso,

${ }^{35}$ Desde la década de 1440 se atestiguan varios individuos de esta familia en Guimarães, pero también en juderías meridionales, en M. José Pimenta Ferro Tavares, Os judeus em Portugal no século XV (Lisboa 1984), vol. II, págs. 156-158, 276, 407 y 520. 
pese a los vínculos familiares con el fiador, las minutas mencionan su condición de vecindad previa en Cea. En efecto, Simuel era sobrino de Manuel Navarro, su fiador, y se compromete:

[...] en esta guisa, que los çinco annos primeros siguientes goze de todas las franquezas e libertades que deven gozar los vezinos nuevos: que no pague monedas, ni pecho, ni repartimiento alguno, ni vele, ni pague otro tributo alguno, que vezino nuevo debe pechar ni contribuyr, salbo que está esento de todas las cosas por los dichos çinco annos primeros siguientes, e que los otros çinco annos peche e contribuya como otro qualquier vezino de esta villa para lo qual dio por su fiador a Manuel Nauarro ${ }^{36}$.

Por consiguiente, los beneficios fiscales derivados de su vecindad estarían limitados a un periodo concreto de la misma ${ }^{37}$. Su tío se obliga a pagar $5.000 \mathrm{mrs}$. para la cámara del conde, además de los pechos y tributos a los que fuere obligado, en caso de que Simuel quebrantara su compromiso. En, al menos, once de los avecindamientos judíos, el fiador es padre, tío, o incluso suegro del interesado, como le ocurre a Simuel, y esa vinculación familiar indica la emancipación de un joven empadronado, al constituir una nueva unidad familiar.

Algo diferentes son los casos de cuatro artesanos judíos avecindados en Villalón, cuya presencia estimula la pujante actividad económica de la villa. Se trata del tejedor Yuçé Mordogay avecindado el 25 de abril de 1473 por diez años $^{38}$, y por el que responde su suegro Ysaque Corcós. La producción de telas y paños debió constituir a nivel local una apreciable fuente de riqueza para el Concejo: también entre los nuevos vecinos cristianos, o bien entre sus fiadores, aparecen mencionados tejedores junto con tintoreros, cardadores, espadadores y tundidores. La presencia de estos últimos en la cadena productiva de la manufactura pañera, distinguió a Villalón como centro destacado en la fabricación de paños de calidad.

Caso similar al anterior es el del chapinero Yuçé Meme, que junto a su hijo David, reciben vecindad en marzo de 1475 por veinte años, y de manera bastante significativa, su fiador es rabý David, «capellán de los judíos», del que no

${ }^{36}$ ARCh, Actas del Concejo de Villalón 1482, f. ${ }^{\circ} 13 \mathrm{v}$.

${ }^{37}$ A semejanza de los «medios vecinos» que menciona Luis García DE VALDEAvEllano, Curso de historia de las instituciones españolas. De los orígenes al final de la Edad Media (Madrid 1973), pág. 543.

${ }^{38} \mathrm{Al}$ especificar su oficio se dice que es «tejedor», no «tejedor de paños», mención esta más precisa aplicada en 1474 a otro cristiano avecindado por veinte años. Mientras que el «tejedor de paños» trabajaba por cuenta propia con telas y paños de su propiedad (a medio camino entre mercader y artesano), aquel era un trabajador manual asalariado integrado en un colectivo. 
tenemos más noticias. Se otorga a Yuçé Meme que los diez primeros años «sean esentos e francos y de todos tributos e monedas; que en adelante, sean obligados a contribuyr con todos los otros judíos». Yuçé residía en la calle Cantarranas, pues sabemos que su casa se traspasa a un cristiano con motivo del segundo apartamiento. Al igual que los hermanos Mosé y Symuel Viejo meses antes, el suyo es un caso de doble avecindamiento simultáneo.

Otro artesano es el colchero Ysaque Rofós avecindado en noviembre de 1479 por quince años. Al igual que Simuel Navarro meses más tarde, su avecindamiento queda «esento e franco de todos los tributos» durante los diez primeros años, pero no durante el resto ${ }^{39}$. Toma por fiadores a Simuel Pex y a don Simuel Ruano y no es el único colchero judío avecindado en Villalón.

En julio de 1481, recibía vecindad por diez años Mosé Alilla, otro colchero procedente de Carrión. Las condiciones explicitadas para recibirlo reflejan el interés del concejo de Villalón por retener a los vecinos: «que no le den huéspedes ni pague otros tributos saluo sy touyere heredad, en fuente e puente e muro de çerca», elevándose la fianza estipulada como garantía de cumplimiento de su avecindamiento a 10.000 mrs. Al igual que Abrahán Querido, Simuel Navarro y, como enseguida veremos rabý Salamón Çalama, el avecindamiento de Mosé Alilla incluye la cláusula de «ser vasallo» del conde, que solamente se menciona después de 1481. Pocos meses después de su avecindamiento encontramos a Mosé Alilla residiendo en la calle Cantarranas, lugar de concentración en Villalón de buen número de judíos.

Finalmente, rabý Salamón Çalama toma vecindad en enero de 1481 por diez años, actuando como fiador rabý Abrahán Alhanate. Las actas del concejo describen las exenciones fiscales de las que, al igual que el resto de vecinos nuevos, se beneficia: «que non le darán huéspedes, nin velas, nin saquen pedido, nin monedas, nin otros tributos ningunos de que los vesinos nueuos non deuen pechar nin contribuyr, e que gelo guardarán por los dichos dies annos». Un año después, rabý Salamón se presenta por acuerdo de la aljama ante el concejo - dos días antes del comienzo de la Pascua judía- junto a Abrahán Alhanate y Abrahán Tamar para pedir «liçençia para meter vna carretada de vino para su Pascua de fuera parte, que no tenían salvo vna caba de vino, e que después de Pascua la beverían» ${ }^{40}$, pues las ordenanzas del concejo no permitían introducir libremente vino de fuera.

\footnotetext{
${ }^{39}$ Otro caso similar es el de Salamón Gabay de Grajal, que recibe vecindad en abril de 1477 por diez años, de los que los cinco primeros con franquicia fiscal.

${ }^{40}$ AMVillalón, Actas del Concejo 1436-1487 (20-I-1481); ARCh, Actas del Concejo de Villalón, f. ${ }^{7} \mathrm{v}$.
} 
NÓMINA DE JUDÍOS QUE TOMAN VECINDAD EN VILLALÓN (1471-1485)

\begin{tabular}{|c|c|c|c|c|}
\hline FECHA & $\begin{array}{l}\text { AVECINDADO, PROFESIÓN } \\
\text { (PROCEDENCIA) }\end{array}$ & VECINO FIADOR & $\begin{array}{l}\text { PARENTESCO } \\
\text { CON EL FIADOR }\end{array}$ & AÑOS \\
\hline $15-\mathrm{II}-1471$ & Rabý Abraham Obadiá & Rabý Simuel & yerno & $20^{c}$ \\
\hline 23-VIII-1471 & Ysaque Calahorrano & Yuçé Corcós, Iacó Corcós & - & 10 \\
\hline 12-IX-1471 & R. Abrahán Alhanate, «físico» & Rabý Mosé Alhanate & sobrino & 10 \\
\hline 9-I-1472 & $\begin{array}{l}\text { Mayr, hijo de Mordogay } \\
\text { Nauarro }\end{array}$ & Manuel [¿Nauarro?] & ¿pariente? & 10 \\
\hline 15-IV-1472 & Yudá Leví & Symuel Ruano & yerno & 10 \\
\hline $5-\mathrm{XI}-1472$ & $\begin{array}{l}\text { Doña Vellida de Cuenca } \\
\text { (de Campos) }\end{array}$ & $\begin{array}{l}\text { R. Abrahán Alhanate, } \\
\text { «físico» }\end{array}$ & madre & 10 \\
\hline 23-XI-1472 & Rabí Abrahán Bellamýn & Rabý Symuel & - & 10 \\
\hline $20-\mathrm{II}-1473$ & Mosé Cabeça & Rabý Daniel, físico & - & 10 \\
\hline 2-III-1473 & Mosé Abén Pex & Don Ça Farache & - & $20^{\mathrm{c}}$ \\
\hline 25-IV-1473 & Yuçé Mordogay, tejedor & Ysaque Corcós & yerno & 10 \\
\hline Finales 1473 & Doña Vellida de Cuenca ${ }^{a}$ & $\begin{array}{l}\text { R. Abrahán Alhanate, } \\
\text { «físico» }\end{array}$ & madre & $10^{c}$ \\
\hline $6-\mathrm{II}-1474$ & Abrahán Obadiáb & Symuel Obadiá & hijo & $10^{\mathrm{c}}$ \\
\hline 6-II-1474 & Mosé y Symuel Viejo & - & - & 10 \\
\hline $6-\mathrm{II}-1474$ & Yudá Viejo & Mosé Viejo & hermano & 10 \\
\hline 7-VII-1474 & Rabý Sentó Alhanate & $\begin{array}{l}\text { R. Abrahán Alhanate, } \\
\text { «físico» }\end{array}$ & hermano & 10 \\
\hline 18-XII-1474 & Rabý Abrahán Crespýn & Lezar Morejón & yerno & 10 \\
\hline 2-I-1475 & Yudá Morejón & Iacó Ruano & - & 10 \\
\hline $10-$ III- 1475 & $\begin{array}{l}\text { Yuçé Meme, chapinero } \\
\text { David Meme }\end{array}$ & $\begin{array}{l}\text { Rabý Dauid, «capellán de } \\
\text { los judíos» }\end{array}$ & - & 20 \\
\hline $19-V-1475$ & Abrahán de Villalobos & Mayr Pex & yerno & 10 \\
\hline 20-XI-1475 & Abrahán Corcós & Yuçé Corcós & hijo & 10 \\
\hline 20-XI-1475 & $\begin{array}{l}\text { Mosé Farache "fijo de Yuçé } \\
\text { Farache que casó en Grajal» }\end{array}$ & $\begin{array}{l}\text { Rabý Acó [¿Morejón?], } \\
\text { «físico» }\end{array}$ & - & 10 \\
\hline 28-IV-1477 & Salamón Gabay (Grajal) & Yudá Gabay & ¿pariente? & 10 \\
\hline 30-XI-1479 & Ysaque Rofós, colchero & $\begin{array}{l}\text { Simuel Pex, don Simuel } \\
\text { Ruano }\end{array}$ & - & 15 \\
\hline 4-I-1481 & Abrahán Querido ${ }^{b}$ & $\begin{array}{l}\text { Abrahán Tamar, Simuel, } \\
\text { platero }\end{array}$ & - & $10^{\mathrm{d}}$ \\
\hline $10-\mathrm{I}-1481$ & Rabý Salamón Çalama & $\begin{array}{l}\text { R. Abrahán Alhanate, } \\
\text { «físico» }\end{array}$ & - & $10^{\mathrm{d}}$ \\
\hline 23-VII-1481 & $\begin{array}{l}\text { Mosé Alilla, colchero } \\
\text { (Carrión) }\end{array}$ & Yuçé Nauarro & - & $10^{\mathrm{d}}$ \\
\hline $3-V-1482$ & Simuel Nauarro (Cea) & Manuel Nauarro & sobrino & $10^{\mathrm{d}}$ \\
\hline 4-III-1484 & Iacó Morejón [«físico»] & - & - & 10 \\
\hline 16-II-1485 & Manuel Ebrudo (Cáceres) & Rabý Daniel, «físico» & - & 10 \\
\hline
\end{tabular}

a Se trata del avecindamiento de la misma doña Vellida que aparece registrada el 5-XI-1472; aquí, además, aporta carta del conde. ${ }^{\mathrm{b}}$ No hemos hallado motivos para identificarlo con su homónimo avecindado el 15-II-1471. ${ }^{\mathrm{c}}$ «Por carta del conde de Benavente». ${ }^{\mathrm{d}} \mathrm{Y}$ «ser vasallo del conde de Benavente». 


\subsection{Avicena en Tierra de Campos}

Especialmente valiosa es la información biográfica de judíos avecindados en Villalón obtenida del examen de manuscritos hebreos. Uno de ellos, rabý Abrahán Crespýn, accede a la vecindad en 1474 de la mano de su suegro, Lezar Morejón, el que años más tarde, en 1482, actúa como procurador de la aljama ante el concejo. Desconocemos de dónde procede y carecemos de indicios que hagan pensar en un arraigo familiar anterior en la villa. Por ello, su acceso a la vecindad estaría vinculado a su matrimonio con la hija de Morejón.

Podemos identificar a Crespýn con el escriba Abraham Ibn Cresp (קברהם) del que se conocen tres manuscritos hebreos conservados que habían sido copiados en Villalón entre 1480 y 1487. Un examen de los contenidos, así como de sus destinatarios arroja luz acerca del ambiente intelectual -caracterizado por unos intereses muy definidos-, dominante en algunos círculos judíos, pero también acerca de las redes personales de los judíos de Villalón cuyo despliegue sobrepasa los límites del señorío.

La copia del primer manuscrito realizado por encargo remunerado de R. Ya'aqob Garzón, del que no hemos logrado reunir noticias adicionales, se concluye en la primavera de 1480. Se trata de una miscelánea de obras de Avicena, incluyendo fragmentos del Canon, seleccionados de distintas versiones hebreas, y su obra Ha-refuot ha-lebiyot, traducción hebrea realizada a partir de una versión latina previa titulada Cordiaca ${ }^{41}$.

Cuatro años más tarde, durante el invierno de 1484, Abraham Ibn Cresp finaliza una copia incompleta del Comentario de Gersónides a la Torá ${ }^{42}$. Se trata también de un encargo, en este caso de Yosef de Milán, hijo de don Šelomó de Milán (יוסף די מילאן יצ"ו... דון שלמה די מילאן יצ"ו). Aunque el manuscrito no ofrece más información acerca del patrocinador, la noticia es interesante por dos motivos: la onomástica remite aparentemente a un judío de origen foráneo, y es bastante verosímil identificarlo con su homónimo rabí Yuçé Milano, menciona-

${ }^{41}$ Ms. BSB Cod.hebr. 373, véase Moritz STEInSCHNEIDER, Die Hebraeischen Handschriften der K.Hof-und Staatsbibliothek in Muenchen (Muenchen 1895²), págs. 208-209; e ID., Die Hebraeischen Uebersetzungen des Mittelalters und die Juden als Doltmetscher (Berlin 1893), § 446b. La fecha judía de finalización (17 de iyyar de 5240) equivale al 27 de abril de 1480. La expresión מקנת כסף 'adquirido mediante dinero' se repite en el colofón de los tres manuscritos.

${ }^{42}$ Ms. Vat. ebr. 35; véase Benjamin Richler (ed.), Hebrew Manuscripts in the Vatican Library. Catalogue. Palaeographical and Codicological Descriptions: Malachi BEIT-ARIÉ in collaboration with Nurit PAsternak (Città del Vaticano 2008), pág. 23. La fecha judía (miércoles, 17 de šebat de 5244) equivale al 14 de enero de 1484. 
do como vecino de Zamora y arrendador en 1490, y mayordomo del duque de Nájera en Amusco y dayán de su aljama dos años después ${ }^{43}$.

Por último, un manuscrito esmeradamente decorado del Canon de Avicena (en la traducción hebrea de Natán ha-Me'atí). El colofón final del manuscrito indica que Abraham Ibn Cresp lo había concluido en 1487 para R. Daniel, hijo de R. Šemuel Daniel ${ }^{44}$. No en vano, las actas de Villalón identifican a rabý Symuel Daniel como uno de los personajes más relevantes de la aljama en 1482: interviene en varias sesiones del concejo, en una ocasión junto con Lezar Morejón, el suegro de Crespýn, como procurador. Rabý Daniel es mencionado en 1473 y en 1485 como fiador en los avecindamientos de Mosé Cabeça y Manuel Brudo, respectivamente. El encargo muestra la capacidad económica de R. Daniel que le permite añadir a su biblioteca un códice tan preciado:

Se completó la copia el domingo, dos de Adar $2^{\circ}$ del año 5247 de la Creación estando en Villalón, y fue adquirida para el honorable, excelente, sabio íntegro y médico admirable R. Daniel, hijo del excelente anciano honorable y excelso sabio íntegro R. Šemuel Daniel ${ }^{45}$.

Contamos con información adicional acerca de las redes personales de la familia Daniel ${ }^{46}$. Dos años antes de concluir la copia de este último manuscrito, rabý Daniel actúa como fiador de Manuel Ebrudo (Brudo), un judío de Cáceres avecindado el 16 de febrero de 1485 en la villa. Aún como vecino de Cáceres, Manuel Brudo había sido víctima en 1472 de su paisano Diego de Sanabria, que tomó en Ciudad Rodrigo su caballo, dinero y otras cosas que portaba «por

${ }^{43}$ Mención a rabí Yuçé Milano, vecino de Zamora, como arrendador y recaudador de alcabalas y tercias de Burgos (1490), en Archivo General de Simancas (en adelante, AGS), EMR, leg. 547a, f. ${ }^{\circ} 3$; acerca de rabí Yuçé Milano, mayordomo de Pedro Manrique en Amusco y padre de rabý Salamón Milano, en CANTERA Burgos, «La administración judía del duque de Nájera», pág. 313.

${ }^{44}$ Se trata del ms. BnF héb. 1136; véase Benjamin Richler, «Manuscripts of Avicenna's Kanon in Hebrew Translation : A Revised and Up-to-Date List» (heb.), Koroth 8 (1982), págs. $145^{*}-168 *$ y $137-143$ (heb.): $§ 71$.

${ }^{45}$ Descripción del manuscrito con transcripción del colofón en Colette SIRAT - Malachi BeITARIÉ, Manuscrits médiévaux en caractères hébrä̈ques portant des indication de date jusqu'à 1540. Tome I. Notices. Bibliothèques de France et d'Israel. Manuscrits de grand format (Jérusalem Paris 1972), n. ${ }^{\circ} 155$ (f. ${ }^{\circ} 345 \mathrm{v}$ ), que leen «Abraham Ibn Qarsaf». La fecha judía equivale al 25 de febrero de 1487.

${ }^{46}$ Menciones a rabí Abrán Daniel y rabí Ça Daniel de Toro en 1491, en Cantera Burgos, «Juderías medievales de la provincia de León», pág. 153; y a don Mošé Daniel de Amusco, en ID., «La administración judía del duque de Nájera», pág. 321. 
fuerça de armas», incidente del que desconocemos los pormenores, pero que no es anómalo ante el desorden político del momento ${ }^{47}$.

A lo largo del siglo XV encontramos menciones a individuos con apellido Brudo en varias localidades del Centro y Sur-Oeste de la Corona, con presencia de varios médicos, aunque de incierta vinculación familiar ${ }^{48}$. No debe confundirse con su homónimo, rabí Manuel Brudo, un coetáneo del autor del Šébet Yehudá -por tanto, de las primeras décadas del siglo XVI-, en donde se le atribuye un tratado de Ta 'amé ha-mișvot ${ }^{49}$. Si la identificación realizada por Uriel Heyd es correcta, este último debería identificarse con Brudus Lusitanus (fl. 1550), un médico al servicio del sultán otomano, hijo de Dinis Rodrigues, el médico personal de João III de Portugal ${ }^{50}$. Teniendo en cuenta los antecedentes familiares y sus vínculos con los Daniel en Villalón no sería aventurado afirmar que el Manuel Brudo avecindado en 1485 hubiera sido también un médico perteneciente a una ilustre familia.

\section{JUDÍOS, VECINDAD Y POLÍTICA DEMOGRÁFICA}

Todos los individuos, a excepción quizás de los hermanos Mosé y Symuel Viejo y de Iacó Morejón, aparecen avalados por, al menos, un fiador que siempre es judío. Su elección no se deja al azar; el criterio principal es la consanguinidad, como también es importante el prestigio del fiador dentro de la aljama: así ocurre con el «capellán» rabý David y alguno de los, al menos, seis avecindamientos avalados por los «físicos» rabý Daniel (2), rabý Abrahán Alhanate (3) y rabý Acó (Morejón).

${ }^{47}$ Tras ser requerido repetidamente para devolver lo sustraído, Diego de Cáceres es emplazado en 1480 por la Corona, en AGS, RGS (18-X-1480), f. ${ }^{\circ} 245$.

${ }^{48}$ Una mención temprana en Ávila, 1414 (Pilar León Tello, Judios de Ávila, Ávila 1963, doc. 78). En las décadas centrales del siglo xv hay referencias a individuos en Granadilla, 1458 (Manuel SERRANo y SANZ, Orígenes de la dominación española en América. Estudios históricos, Madrid 1918, pág. 266); Sevilla, 1460 (Klaus WAGNER, Regesto de documentos del Archivo de Protocolos de Sevilla referentes a judíos y moros, Sevilla 1978, n. $\left.{ }^{\circ} 16\right)$; Santa Olalla y Toledo, 1468-1492 (Pilar León Tello, Judíos de Toledo, Madrid 1979, vol. I, doc. 91; vol. II, docs. 1070, $1240,1174,1228$ y 1380).

${ }^{49}$ Séfer Šébet Yehudá le-rabí Šelomó b. Verga, ed. Yișhaq BAER y comentarios de Azriel S̆онат (Jerusalem 1947), § 64, pág. 141.

${ }^{50}$ Uriel HeYd, «An Unkwnown Turkish Treatise by a Jewish Physician under Süleymān the Magnificent», en L. A. Mayer Memorial Volume [= Eretz-Israel 7] (Jerusalem 1964), págs.*48*53; Harry FrIEDENWALD, «Immortality Through Medical Writ of Error. Dionysius: A Portuguese Jewish Court Physician. With Notes on Brudus Lusitanus, His Son and on Pierre Brisot», reimpr. en su The Jews and Medicine. Essays (Baltimore 1944), vol. II, págs. 460-467. 
No hay que olvidar que estamos ante un concejo de señorío, lo que explica que hasta en cuatro ocasiones el individuo avale su avecindamiento, además, con una carta del conde de Benavente, como la entregada por rabý Abrahán Obadiá, «en que [el conde] manda que le den vezindad». Ello está en consonancia con la extendida intervención de la nobleza en distintos aspectos de la vida urbana, no sólo, como era de esperar, en concejos de señorío, sino también en los de realengo. Eso explica las actuaciones por separado de Pedro Fajardo, adelantado de Murcia, y de su mujer en 1460 ante los alcaldes y regidores de ese concejo para favorecer la concesión de vecindad a judíos ${ }^{51}$.

¿Cómo podemos interpretar la concesión de vecindad a judíos? Es evidente que, con la documentación disponible, no se puede hablar de un fenómeno generalizado, sino que está sometido a las circunstancias locales, como tampoco existía unanimidad política respecto a su otorgamiento ${ }^{52}$.

Cabría precisar primero las implicaciones directas que para un judío tiene la concesión de vecindad. La documentación de Villalón se refiere genéricamente al disfrute común de las franquicias fiscales y libertades que gozaban los vecinos nuevos y sólo en casos excepcionales ofrece detalles más explícitos.

La carta de vecindad de rabý Salamón Çalama precisa alguna de las exenciones extendidas a los vecinos nuevos: «huéspedes, nin velas, nin saquen pedido, nin monedas, nin otros tributos ningunos». La carta de Mosé Alilla añade, no obstante, el deber de participar en cargas vecinales «sy touiere heredad, en fuente e puente e muro de çerca» ${ }^{53}$.

La vecindad era resultado de una negociación continua entre dos partes, y por ello dependía de las circunstancias coyunturales de cada judío. Aparentemente, rabý Abrahán Alhanate gozaba de una situación privilegiada como «físico» al servicio del concejo que le permitía aparecer como fiador en la concesión de vecindad de tres personas, entre ellas su hermano y su madre.

${ }^{51}$ Juan Torres Fontes, «Murcia Medieval. Testimonio documental», Murgetana 68 (1985), págs. 79-130: 83. Otros como Abenjamín Abenyahión, siguen presentando fiador (en su caso, rabí Uçef Abenyahión), véase Luis RuBio García, Los judíos de Murcia en la Baja Edad Media (13501500). Colección documental (Murcia 1994), vol. II, doc. 908 (11-III-1476).

${ }^{52}$ Aunque referida a Portugal, es elocuente la prohibición de concesión de vecindad a judíos ordenada por el infante Duarte (ca. 1412-1433), luego rey, insertada en las Ordenações Afonsinas (Coimbra 1786), libro II, tít. 79. Con todo, la documentación lusitana registra algún caso excepcional de concesión por intermediación del rey, véase TAVAREs, Os judeus em Portugal no século XV (Lisboa 1982), vol. I, pág. 224.

${ }^{53}$ Un texto citado en la nota 5 supra señala la obligación de que los judíos contribuyan con el resto de vecinos en derramas para la realización de determinadas obras públicas. La derrama para la reparación de un puente fue publicada por M. ${ }^{a}$ Fuencisla GARCÍA CASAR, Fontes Iudaeorum Regni Castellae. VI. El pasado judío de Ciudad Rodrigo (Salamanca 1992), pág. 72. 
En general, la concesión tenía una vigencia de diez años. Excepcionalmente, ascendía a quince o veinte años, aunque la franquicia fiscal convenida sólo cubriera la mitad, como sucede a Ysaque Rofós y Yuçé Meme, obligados a tributar «con todos los otros judíos» los diez años restantes ${ }^{54}$. Salamón Gabay de Grajal recibía vecindad por diez años, pero su dispensa incluía únicamente los cinco primeros, al igual que Simuel Nauarro de Cea.

Además de las exenciones fiscales, otro elemento a tener en cuenta a la hora de entender la vecindad está relacionado con el desarrollo económico de la villa y las ferias, en concreto, con el requisito de vecindad recogido por las ordenanzas concejiles (redactadas a comienzos del siglo XVI) para poder ejercer una serie de oficios a lo largo de todo el año.

Resulta engañoso pensar que las concesiones de vecindad abrieran una vía a una mayor integración de los judíos en la vida social. También se podría razonar que dicha categoría jurídica podría desdibujar la pertenencia a una comunidad, la judía, construida sobre pilares socio-familiares y religiosos. Y ello, como si una categoría formal, cuyo contenido y significado no era tan evidente ${ }^{55}$, pudiera imponerse frente a una lógica contraria inspirada por la consideración de los judíos como casta.

Un análisis de las redes personales permite ver cómo pese a los criterios económicos -y los beneficios derivados de ellos-, que reciben consideración prioritaria en la aspiración por la vecindad, no se advierten cambios significativos relacionados con factores personales o cívicos. Es de sobra revelador que, pese a una reducción sensible del número de concesiones, se sigan produciendo avecindamientos con posterioridad al segundo apartamiento de 1482, siquiera excepcionalmente.

La concesión de vecindad a judíos se asocia fundamentalmente a una época de fragmentación y desorden político, durante el que las instancias locales de poder, señorial y concejil, incrementan su protagonismo. Aparte de la motivación económica, la vecindad es un instrumento en manos de los poderes locales para el establecimiento de unas directrices demográficas, que identifican el número y la consistencia de la población como elementos de riqueza para los gobernantes lo-

${ }^{54}$ En el caso de las concesiones por veinte años a rabý Abrahán Obadiá y a Mosé Abén Pex no se especifica si la franquicia cubre todo el periodo.

${ }^{55}$ Desde un punto de vista teórico, véase Félix MARTínez Llorente, «El régimen jurídico de la vecindad medieval y las novedades del ius commune», en Las sociedades urbanas en la España medieval (Pamplona 2003), págs. 51-80: 72-77; Julius KIRSHNER, «Civitas Sibi Faciat Civem: Bartolus of Sassoferrato's Doctrine on the Making of a Citizen», Speculum 48 (1973), págs. 694713. Son importantes las reflexiones metodológicas recogidas en Tamar HerzoG, «La vecindad: entre condición formal y negociación continua. Reflexiones en torno a las categorías sociales y las redes personales», Anuario del IEHS [Instituto de Estudios Histórico-Sociales] 15 (Buenos Aires 2000), págs. 123-131; ampliadas luego en EAD., Defining Nations. Immigrants and Citizens in Early Modern Spain and Spanish America (New Haven \& London 2003). 
cales. No en vano, algunos de estos vecinos judíos son médicos y artesanos, hecho que responde a intereses específicos, económicos y de prestigio, de la localidad.

Si la vecindad ha sido vista como un factor de integración solidaria superpuesta a otros vínculos asociativos, comenzando por el familiar, un análisis del avecindamiento de judíos de Villalón, muestra que ambos niveles, social y familiar, se superponen, pues fiador y familiar se identifica en, al menos, la mitad de los casos. Además, el hecho de que, sin excepción, los fiadores de nuevos vecinos judíos también sean judíos, reflejo de una segregación social de facto, convierte ciertos aspectos del avecindamiento en una ficción jurídica.

En realidad, el avecindamiento de los judíos apenas tiene más efectos palpables que los fiscales y laborales. Por otro lado, no se puede olvidar que la vecindad se convierte en un dispositivo de supervisión de la aljama y de sus judíos por el concejo, a la vez que les garantiza un reconocimiento legal y su integración segregada dentro de la sociedad local. A través del avecindamiento, los judíos reconocen la primacía del concejo y le prestan juramento de lealtad.

Con todo, el avecindamiento de los judíos, junto a otros factores como, por ejemplo, su implicación en la red de asistencia médica local, resulta un termómetro aceptable para medir la integración condicionada de los judíos en la vida urbana, y la necesidad que la sociedad mayoritaria tiene de ellos.

Retomando la vecindad de rabý Abrahán Alhanate, lo cierto es que la anotación realizada al margen de su minuta precisaba que era «salida su franqueza». En efecto, once años después de haberse avecindado en Villalón, aparece mencionado en septiembre de 1482 como vecino de Medina de Rioseco ${ }^{56}$.

En el curso del trienio precedente rabý Abrahán había venido reclamando del concejo el pago de su salario, que había dejado de pagarle en 1479 «porque la villa está en nesçesidad». La reclamación resultó infructuosa, pese a las instrucciones del conde de Benavente que había urgido por carta un acuerdo para abonarle dos tercios de la deuda. No sólo eso, sino que a raíz del apartamiento, el concejo, soslayando las instrucciones del conde, había suspendido el 20 de mayo de 1482 su contrato, junto con el del «físico» rabí Acó Morejón ${ }^{57}$. Su traslado a Medina de Rioseco se saldó con la toma por el concejo de «axuar e

\footnotetext{
${ }^{56}$ ARCh, Actas del Concejo de Villalón, papel suelto (20-IX-1482).

${ }^{57}$ Algunos aspectos relativos al avecindamiento tratados en este artículo han sido objeto de estudio con otro enfoque por Susana del Rey Granell en su trabajo de DEA titulado Una aljama judía en Tierra de Campos durante el siglo XV: el avecindamiento y la segregación de los judios de Villalón (UCM 2007). El estudio de los judíos de Villalón y Mayorga en sus relaciones con la sociedad circundante, con interés especial por la vinculación con Portugal, se lleva a cabo en su tesis doctoral en curso bajo la dirección de Javier Castaño.
} 
ropa» que había quedado en Villalón, sin que conozcamos los detalles exactos de este desenlace.

\section{APÉNDICE DOCUMENTAL}

1437, junio 28, jueves

Acta del avecindamiento en Villalón de Yudá de Aguilar por diez años.

AMVillalón, Actas del Concejo 1436-1487, f. ${ }^{\circ} 19 \mathrm{v}$

En este dicho día, ante los dichos alcaldes e regidores tomó vesindat Yudá de Aguillar, judío, por dies annos conplidos primeros siguientes e los dichos alcaldes e regidores reçebiéronle por vesino a el dicho Yudá, judío. Dió por su fiador a Pero Manuel, vesino desta villa, el qual se otorgó por tal fiador e se obligó de atener e guardar e conplyr lo quel dicho Yudá non conpliere. Carta firme. Testigos: Juan de Vergara e Diego Panero e Pero de Amaya.

Este día, el dicho Yudá, judío fiso juramento segund su Ley de morar en esta villa los dichos dies annos so pena de perjuro. Carta firme. Testigos los sobredichos.

2

1471, septiembre, 12

Minuta del avecindamiento en Villalón de rabý Abrahán Alhanate, físico, por 10 años saliendo como fiador su tío rabý Mosé Alhanate.

AMVillalón, Cuaderno de Minutas de avecindamientos, $f .^{o} 1 v$.

En miércoles XII de septienbre, antel dicho corregidor e regydores, rabý Abrahán Alhanate, judío fýsyco, tomó vezindad por dies annos, en esta manera que le sean guardadas todas las franquezas e libertades que se acostunbran guardar a todos los otros fýsycos que en esta villa han vevydo e viven e que se le guarden estas franquezas mientra el aquý vevyere e usare del ofiçio de fýsyco, e servyere a la dicha villa, e los dies annos que viva en ella e dio por su fiador a rabý Mosé Alhanate, su týo. Testigos, etc.

[Al margen:] Es salida su franqueça. rabý Abrahán Alhanate, fiador rabý Mosé Alhanate.

3

1472, noviembre, 5

Minuta del avecindamiento en Villalón de doña Vellida de Cuenca (de Campos) por 10 años. Actúa como fiador su hijo rabý Abrahán Alhanate. En 1473, se reitera la concesión "por virtud de una carta del conde» de Benavente ( $f^{\circ} 3 r$ ).

AMVillalón, Cuaderno de Minutas de Avecindamientos, $f^{\circ}{ }^{\circ} 2 r$.

En jueves, çinco de novyenbre, antel liçençiado Pedro de Santoyo, corregydor e Alonso Garçía e Juan Martínez de Valdeasillas, alcaldes, ante Diego Sánchez de Monylla e Juan de Soto e Juan Calderón, regydores, tomó vezindad doña Vellida de Cuenca, muger de rabý Salamón de Cuenca, fýsyco, por dies annos, e fizo juramento, e dio por su fiador a rabý Abrahán Alhanate, su fijo. Testigos, etc. 
[Al margen:] Vive en la villa doña Vellida, fiador Raby Abrahán, su fijo»].

1481, enero 4, jueves

Acta del avecindamiento de Abraham Querido ante el concejo de Villalón.

AMVillalón, Actas del Concejo 1481-1499, f. ${ }^{\circ} 11 v-12 v$.

Paresçió aý presente Abrahán Querido, judío, vesino que dixo que era de Grajal cabe Sant Fagund, e dixo que él quería ser vasallo del conde nuestro sennor e vesino desta villa, e quería tomar en ella veçindad por dies annos dándole las franquesas e libertades que se dan a otros vesinos nueuos que se vienen a beuir a esta dicha villa. E luego, la dicha justiçia, regidores e procurador dixieron que les plasía de su vesindad pora vasallo del conde nuestro sennor e vesino desta dicha villa, e que le querían dar la dicha vesindad por los dichos diez annos con tanto que diese fianças para beuir en esta dicha villa los dichos dies annos, e que le darían todas las franquesas e libertades que dauan a otros vesinos nueuos desta dicha villa. E luego, el dicho Abrahán Querido dixo que quería ser vasallo del conde nuestro sennor e que quería ser vasallo de su sennoría e vesino desta dicha villa, e que açeptaua e açeptó e tomaua e tomó de la dicha justiçia e rexydores e procurador la dicha vesindad por los dichos diez annos e que se otorgaua e otorgó por tal vesino, e obligó a sý e a sus bienes de veuir en esta dicha villa / los dichos dies annos e ser vesino della so pena de çient mill mrs. que sobre sý puso de pena para la cámara del conde nuestro sennor. Por lo qual asý a tener guardar e conplir dió por sus fiadores que aý estauan presentes a Symuel, platero, e Abrahán Tamar, judíos desta dicha villa, los quales se otorgaron por sus fiadores que veuirá en esta dicha villa los dichos dies annos conplidos, e sy non venrá a veuir en esta dicha villa, que obligó a sý e a sus bienes, todos pierda, e pagar al conde nuestro sennor çient mill mrs. para su cámara e a pagar todos los dapnnos e costas que sobre la dicha rasón e por él sy non se viene a veuir a esta dicha villa se reqresçieren. E la dicha justiçia e rexydores e procurador quedaron de le dar qualquier libertad que dan a los otros vesinos nueuos, e de non le dar huéspedes nin otras cosas que a los semejantes non se deuan faser. Anbas las dichas partes otorgaron carta fuerte e firme con renunçiaçiones de leyes e fueros e derechos. Testigos qu'estauan presentes: Juan Ortys e Alonso de Verdesoto e Rodrigo de Vega el Moço, vesinos de la dicha villa de Villalón. /

E luego en contynenty, el dicho Abrahán Querido judío obligó a sý e a sus bienes muebles e raýses avidos e por aver, sy por cabsa de él non se venir a beuir a esta dicha villa por los dichos dies annos conplidos e ser vasallo del conde nuestro sennor e vesino desta dicha villa, e los dichos Symuel, platero, e Abrahán Tamar, judíos vesinos desta dicha villa por lo fiar en la dicha vesindad de los dichos dies annos a ellos veniere algund dapnno o les fuere saneada la dicha pena de los dichos çient mill mrs. para la cámara del conde nuestro sennor, quél obligó a sý e a sus bienes de los sacar a pas e a saluo [...].

Recibido: 02/12/2006

Aceptado: 18/01/2009 (versión final) 